\title{
Organizational Predictors of Employees' Burnout and Engagement Experiences
}

\section{Bunga Indira Artha ${ }^{\mathrm{a}}$ and Arum Etikariena Hidayat ${ }^{\mathrm{b}}$}

${ }^{a}$ Faculty of Psychology, Universitas Indonesia, Depok, Indonesia; ${ }^{b}$ Department of Industrial and Organizational Psychology, Faculty of Psychology, Universitas Indonesia, Depok, Indonesia

*Corresponding author:

Arum Etikariena Hidayat

Department of Industrial and Organizational Psychology

Faculty of Psychology, Universitas Indonesia

Jl. Lingkar Kampus Raya, Depok, Jawa Barat

Indonesia, 16424

Tel.: +62 217270004

Email address: arum.etikariena@ui.ac.id / arum.hidayat@gmail.com 


\title{
Organizational Predictors of Employees' Burnout and Engagement Experiences
}

\begin{abstract}
This paper presents a model on how the degree of fit between a person and a work environment within the six areas of work life-including workload, control, reward, community, fairness, and values - determines the extent to which the employee experiences what is described as engagement and burnout. A sample of 160 full-time Indonesian employees was involved in cross-sectional research. The data were collected using a questionnaire consisting of the Maslach's Burnout Inventory-General Survey, the Utrecht Work Engagement Scale, and the Areas of Work-life Scale to measure employees' level of burnout and engagement, as well as the degree of congruence with their work environment. To explore the relationships among measured variables, the hypothesized models were tested using a structural equation model. The proposed model shows a good fit in which the result satisfies all the fit indices used. The influence of employees' match with workload, reward, community, and fairness on burnout was negative and statistically significant. A match in the workload had a positive, statistically significant influence on work engagement. Management must realize employees' degree of congruence with the work environment is an essential predictor of their engagement and burnout experience. This article complements the literature on occupational health psychology by explaining the degree of congruence with the work environment influences engagement and burnout level in the Indonesian workforce.
\end{abstract}

Keywords: burnout, engagement, areas of work-life, workload, reward, community, fairness

\section{Introduction}

Today, organizations must adapt to rapid and continuous technological and social changes. Previously, organizations largely responded to this situation by modifying the traditional organizational structures to achieve desired control mechanisms and chain of command. Other organizations work with economic principles, including encouraging cost reduction and work efficiency. Unfortunately, focusing on both of these approaches is not enough. Twenty firstcentury organizations also place a strong emphasis on human capital management (Schaufeli, Leiter, \& Maslach, 2009). Furthermore, Bakker, Albrecht, and Leiter (2011) argue that in the information and service economy of the new century, people exclusively place critical emphasis on employees' work experiences in the psychological connection with their work.

As previous research on occupational health psychology shows, employees' overall personal and professional life quality threatened by job stress is a significant work hazard. This aspect includes one's physical health, psychological well-being, and work performance. Such findings encouraged the researcher to deeply explore working conditions and then discover a phenomenon called "burnout." Burnout is a term coined to explain the experience of fatigue 
caused by prolonged job-related stress (Maslach, Schaufeli, \& Leiter, 2001). Beginning with the phenomenon in the services sector organization in which employees do "people" work, the concept of burnout caught the attention of many researchers and practitioners. However, a long journey of study and practice shows this issue also exists in other professions and occupational groups (Schaufeli, Salanova, Gonzalez-Roma, \& Bakker, 2002).

A recent Gallup survey on approximately 7,500 full-time employees revealed that $23 \%$ of the sample reported experiencing burnout at work with "very often" or "always" intensity (Wigert, \& Agrawal, 2018). Another $44 \%$ of the respondents reported sometimes feeling burnout at their job. Moreover, a study on 614 Human Resource professionals revealed that $46 \%$ mention burnout experiences in the workplace as being responsible for $20 \%-50 \%$ of the turnover rate in their organization (Kronos Incorporated, 2017). This is in line with other research that explained burned-out employees are twice as likely to leave the organizations than their more engaged peers (VITAL WorkLife, 2018).

Although many workers consider burnout as part of the job, the actual organizational cost of this experience is substantial (Wigert, \& Agrawal, 2018). Employees who experience burnout are $63 \%$ more likely to take sick leave. A burned-out employee is also 2.6 times as likely to be actively seeking a new job. For those who withstand the distress, burnout leads to decreased effectiveness and lower productivity at work (Maslach et al., 2001). When employees shift to minimum work quality, rather than giving their best performance, they make more mistakes, become less accurate, and have fewer ideas (Maslach \& Leiter, 2010).

Leiter and Maslach (2003) explained burnout as a psychological syndrome which is a response to the ongoing prolonged chronic external stimulus exhibited by stress on the job. In burnout, the emphasis is placed on the process of psychological erosion, rather than just the physical. The burnout experience is portrayed as "the smothering of a fire" or "the extinguishing of a candle" (Schaufeli, Leiter, \& Maslach, 2009). It implies that unless there are sufficient resources filled continuously, where once a fire was burning, the flame cannot continue blazing. The employee entered a job with loads of resources generated from positive expectations, intense enthusiasm, and the purpose of completing the task successfully (Maslach et al., 2001). Over time, the spirit fades, and now the employee is filled with overwhelming exhaustion, cynicism, and a sense of ineffectiveness.

This burnout experience is described as an overwhelming feeling of exhaustion, cynicism, and ineffectiveness (Maslach et al., 2001). Emotional exhaustion is the primary quality of burnout. It reflects the strained dimension of this experience. Employees might find themselves "running out of gas" and eventually reaching the point where they cannot seem to focus on the task on hand. Exhaustion is not the only thing experienced; instead, this prompts actions to distance oneself emotionally and cognitively from one's work. In order to cope with their limited energetic resources and protect themselves from further emotional depletion, burned-out employees reduce their involvement with their job. This immediate reaction to exhaustion called cynicism. Cynicism is indicated by a cognitive distancing in which the employee is developing an indifference or cynical attitude toward his/her work. 
Working in a condition with constant and overwhelming demands leads employees to experience exhaustion and cynicism. Over time, it is susceptible to eroding one's sense of effectiveness. When an employee feels exhausted and cynical about the significance of his/her work, it is hard to develop a sense of accomplishment. In general, the vast research on burnout has settled the subsequent link between the draining of emotional resources and a cynical attitude toward one's job. However, the following connection to inefficacy is less clear.

Furthermore, Gonzalez-Roma, Schaufeli, Bakker, and Lloret (2006) criticized feelings of lack of accomplishment and inefficacy as reflecting a personality characteristic, rather than an actual burnout component. This conclusion is in line with Schaufeli et al. (2002), whose study aimed to examine the factorial structure of burnout and engagement using 933 samples of university students and employees. A factor analysis result showed that burnout (as characterized by exhaustion and cynicism) with an extended engagement factor (including efficacy) fits best to the data of both samples. Therefore, they concluded exhaustion and cynicism are the core of burnout, leaving out the inefficacy dimension.

Maslach et al., (2001) explain that the occupational psychology researcher and practitioner used to focus more on negative states (the 4Ds: disease, damage, disorder, and disability), rather than on human strength and optimal functioning. However, the emerging trend toward "positive psychology" has led researchers and experts to direct more attention within the study on energy and dedication as fundamental dimensions of existence. Following the mainstream, burnout positive antithesis - engagement - also began to obtain attention. People now extend their interest to the positive side of a worker's well-being, rather than focusing solely at the negative pole (Schaufeli et al., 2002).

In recent years, a significant number of reports on engagement surveys and scientific studies have become available for public access. Many have claimed employee engagement predicts bottom-line outcomes, such as higher performance and productivity (Gallup, 2013); organizational success as indicated by job satisfaction, organizational commitment, intention to quit, and organizational citizenship behavior (Saks, 2006); and financial performance seen from higher sales and total shareholder return (Schaeffer, 2018).

Work engagement is defined and operationalized as "a positive, fulfilling, work-related state of mind that is characterized by vigor, dedication, and absorption" (Schaufeli et al., 2002). Vigor is a behavioral-energetic component of engagement, where an employee has levels of energy and mental resilience while working. The engaged employee is willing to invest his/her effort and show persistence even when he/she encounters challenges at work. Dedication entails emotional components in which the employee has a sense of significance, enthusiasm, inspiration, and pride toward his/her job. The dedicated employee describes his/her job as challenging and meaningful; thus rather than merely "doing one's job," he/she is also willing "to go the extra mile." Energetic and inspired employees are absorbed in their jobs. Absorption is the cognitive component of engagement characterized by being fully concentrated and deeply engrossed in one's work. While working, engaged employees feel carried away with their task and feel time passes quickly. 
Taris, Schaufeli, and Shimazu (2010) portray engaged employees as individuals who work hard and are involved and happily engrossed in their work. Therefore, having engaged employees who possess work motivation, proactive in solving problems, responsible for their duties, and involved in their job helps the organization to thrive. Moreover, in his paper, Saks (200) mentioned that engaged employees are also more favorable to develop a positive relationship with the organization and show high-quality attitudes, intentions, and behaviors. Engaged employees who have the initiative, who are responsible, and who are commited for high-quality performance standards are a rare and expensive resource organizations must possess in order to gain competitive advantages (Leiter \& Bakker, 2010).

A popular theme throughout burnout and engagement works is the presence of a problematic relationship within an individual's characteristics and their work environment (Leiter, \& Maslach, 2003). This phenomenon is often described as a disparity, misalignment, or poor fit to reflect the gap in employee preference and actual condition. Furthermore, Maslach and Leiter (2010) explain how workplaces shape employees' well-being experience. When employees perceive there are significant mismatches between their preference and the nature of the job, they are at a higher risk of experiencing burnout. Conversely, a perceived fit between the employee and the job they do is more likely to develop engagement.

According to Lewin's field theory (1951), "individuals' behaviors are dependent on their work environment." As the individual's behavior and their work environment are inseparable entities, their interaction results in the development of specific behaviors and attitudes. Employees who perceived their work environments positively also tend to exhibit positive behaviors. Employees' perceptions of a good fit with the organization lead them to engage with their work. On the opposite continuum, those who perceive less organizational fit are predicted to exhibit burnout.

Based on in-depth research on more than 10,000 employees across a broad range of organizations in several countries, Maslach and Leiter (2010) found most person-job misfit could be grouped as six major work-life areas: workload, control, reward, community, fairness, and values. A workload is the amount of work, the kind of work, the pace of work, and the demands of work. Control is described as the amount of autonomy employees can exercise over their job. Reward consists of financial, institutional, social, or intrinsic rewards. Community represents people in employees' social work environments. Fairness is respect and fair treatment in the workplace. Finally, values portray ethical conflicts while doing the job.

Adapted from the demand-control model of job stress proposed by Karasek and Theorell (1990), Leiter and Maslach (2003) proposed workload and control area. The key idea behind this model is that control buffers the impact of workload on strain by providing a resource. This resourceful environment helps employees to engage in challenging tasks and learn new skills. Reward refers to the use of reinforcements to shape people's behavior. As described in the effort-reward imbalance model, experiencing a lack of reciprocity concerning effort spent and low gain received elicits a negative relationship between the employee and the organization (Siegrist, 2017). 
Community represents employees' social support and conflict occurring within; this area is related to the human need for autonomy and the need to belong (Leiter \& Maslach, 2003). Fairness is adapted from the study on equity and justice in the workplace. It refers to how the quality of the procedures and the treatment among workers communicate respect and confirms their self-worth. Lastly, the area of values represents the cognitive-emotional power of job goals and expectations. A positive experience flourishes in work settings in which there are strong connections between the organization and personal values.

These six areas reflecting essential job relationship are linked both theoretically and empirically to the development of burnout and engagement experience in the workplace (Maslach et al., 2001). The higher the gap between the employee preference and the actual work environment, the higher the possibility of burnout. Conversely, the higher the perceived fit, the higher the likelihood of experiencing engagement with ones' work. In each area, where the nature of the job is perceived as not in the right balance with the people doing the work, it results in the experience of exhaustion, cynicism, and inefficacy (Leiter, \& Maslach, 2003). Conversely, when employees perceive better compatibility in these six areas, then engagement with work is the likely outcome.

Based on the theoretical discussion above, Fig. 1 represents the proposed path model of the six areas of work life as organizational predictors and work experiences describe as burnout and engagement. Burnout experience is characterized by feelings of exhaustion and cynicism, whereas engagement embodies vigor, dedication, and absorption in one's work.

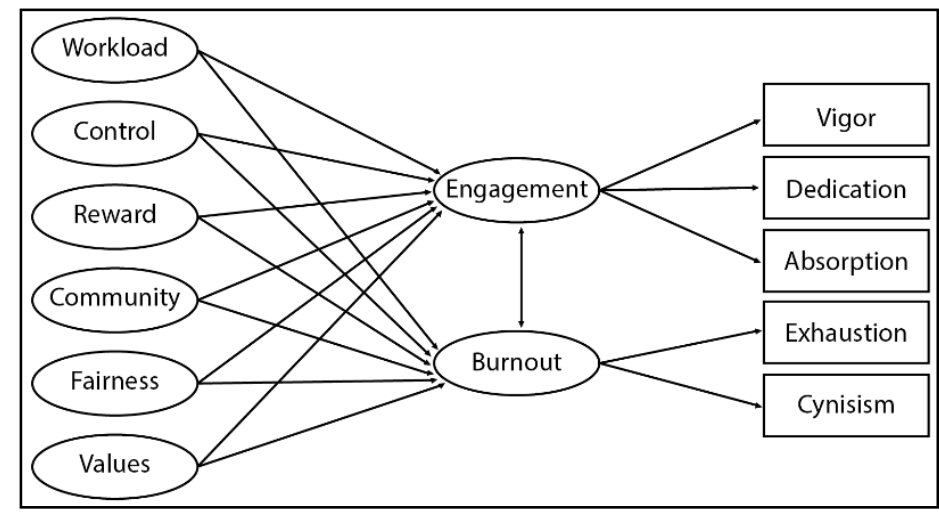

Fig. 1. Proposed organizational predictors of burnout and engagement model.

Unfortunately, studies on burnout and engagement within the Indonesian workforce have never examined this complete model before. As a result of an extensive exploration of Indonesian online research databases (https://www.neliti.com/id/ and http://garuda.ristekdikti.go.id/) shows, there are only two research papers that explore burnout and engagement simultaneously. Both of those research efforts aimed to explore the relationship between employee engagement and burnout using the correlation technique (Hikmatullah, 2017; Christianty, \& Widhianingtanti, 2016). These studies do not account for the antecedent of both concepts and encourage the next studies to include external factors that might be involved in employees' burnout and engagement experience. The State of the Global Workplace study by Gallup (2013) shows that only $8 \%$ of Indonesian employees report feeling engaged with their work, and $15 \%$ 
are actively disengaged. In this instance, an organization should identify the perpetrator behind this founding, or else, their business and the Indonesian economy in general might be left behind the competition in the next few years.

Hence, the present study intends to help management to identify the role the work environment factor plays on the emergence of employees' burnout and engagement experience. Based on the literature study from existing research, this study tested the proposed model (see Fig. 1) in order to answer the proposed research question: "How the degree of fit or congruence between the person and the work environment predict employees' experiences of burnout and engagement?"

\section{Methods}

\section{Research Design and Procedure}

This study utilized quantitative methods taking the form of a cross-sectional design. The data were collected using a questionnaire consisting of the Maslach's Burnout Inventory-General Survey (MBI-GS), the Utrecht Work Engagement Scale (UWES), and the Areas of Work-Life Scale (AWS) to measure employees' burnout, engagement, and perception of work environment, respectively. A professional translator translated all measurement instruments used in the study from English to Bahasa Indonesia (Indonesian language). The questionnaire was then validated by a number of industrial and organizational (I/O) practitioners. Respondents were also asked to provide their demographic data consisting of gender, education level, year born, and year of employment.

This study investigated whether the degree of congruence between an employee and their work environment relates to their level of engagement and burnout and aimed to show that a higher degree of fit with one's work environment has a positive effect on engagement, whereas a higher degree of misfit results in higher levels of burnout. The researcher utilized various online messaging and social media sites to send the targeted respondent invitations to complete the research questionnaire. The link provided in the message took participants to the online websitehosted survey (Universitas Indonesia Survey http://survey.ui.ac.id/web/). Researchers also handed out a paper-based questionnaire to 130 employees, and 123 copies were completed and returned (94.62\% response rate). The consent form attached to the survey informed participants about the general information of the study and the confidentiality of the data.

\section{Measurement Instruments}

\section{Burnout}

Burnout was measured using the Exhaustion (Ex) (five items, e.g., "I feel emotionally drained from my work") and Cynicism (Cy) (five items, e.g., "I have become more cynical about whether my work contributes anything”) scales from Maslach's Burnout Inventoy-General Survey (MBI-GS) (Maslach, Jackson, Leiter, \& Schaufeli, 1996). On a 7-point Likert scale ranging from 0 ("never") to 6 ("always") respondents indicated how often they have experienced each statement. High scores on the scales are indicative of burnout. The result for internal consistencies (Cronbach's $\alpha$ ) for the used MBI-GS was 0.83 . 


\section{Engagement}

The UWES (Schaufeli \& Bakker, 2003) was used to measure three dimensions of engagement: Vigor (six items, e.g., "At work I feel bursting with energy"), Dedication (five items, e.g., "The work I do has meaning and purpose"), and Absorption (six items, e.g. "Time flies when I'm working"). Items were answered by representing the frequency of each experience using a 7point Likert scale from 0 ("never") to 6 ("always"). Higher scores on the UWES indicate higher levels of employee engagement. High scores on the three scales are indicative of engagement. The result for internal consistencies (Cronbach's $\alpha$ ) for UWES was 0.93.

\section{Areas of work-life}

The AWS (Leiter \& Maslach, 2000) was used to assess the degree of congruence in each of the six areas of work life. The workload dimension consists of three items (e.g., "I do not have time to do the work that must be done"). The control dimension is measured by three items (e.g., "I can influence management to obtain the equipment and space I need for my work"). The reward dimension has three items (e.g., "My work is appreciated"). The community dimension is assessed by five items (e.g., "Members of my workgroup cooperate with one another"). The fairness dimension is evaluated in four items (e.g., "Management treats all employees fairly"). Finally, the value dimension composed of four items (e.g., "My values and the organization's values are alike").

Respondents reported their level of agreement with each statement on a 5-point Likert scale ranging from 1 ("strongly disagree") through 3 ("hard to decide") to 5 ("strongly agree"). The negatively worded statements were scored reversely. Each of the subscales obtained the degree of person-job fit. A high score on the AWS indicates a higher degree of congruence between the workplace and the respondent's preferences. A lower score reflects more incongruence between the worker and the workplace. The result for internal consistencies (Cronbach's $\alpha$ ) of AWS was 0.85 .

\section{Data Analysis}

The model in Fig. 1 was examined using structural equation modeling (SEM). The statistical analysis method was selected based on its strength to test and validate complex models including multiple constructs with a complicated relationship. The hypothesized model was evaluated based on the chi-square test statistic, and three fit indices consist of CFI, RMSEA, and SRMR (Hu, Li-Tse, \& Bentler, 1999) In order to conclude if the model represents an acceptable fit to the population data, the result must meet the majority of the desirable criteria. The hypothesized model was tested against data from the samples using package Lavaan 0.6 series run in RStudio version 1.1.456 for Windows.

\section{Participants}

The model proposed was tested in the Indonesian workforce represented by a convenience sample of 160 employees. All participants were full-time employees from both public and private sector organizations; have a minimum high school graduate degree; and have been employed in the present organization for at least one year. Of the participants, $51.9 \%$ were female, and the others (48.1\%) were male. Participants' ages ranged from 22 to 57 years old (M 
$=36.80, \mathrm{SD}=10.24)$, with tenure of $1-38$ years $(\mathrm{M}=10.97, \mathrm{SD}=9.30)$. The education range for the sample included bachelor's degrees (56.3\%), high school (18.1\%), master's degree $(13.1 \%)$, baccalaureate $(10.6 \%)$, and doctorate $(1.9 \%)$.

\section{Results}

\section{Descriptive Statistics and Correlations}

A correlation analysis was run to obtain the strength and direction of the relationship between the variables in the model. The result is reported in Table 1 . The descriptive statistic for all variables includes mean and standard deviation, which is also covered by the table.

Table I. Means, Standard Deviation, and Correlation for the Study Variable

\begin{tabular}{|c|c|c|c|c|c|c|c|c|c|c|c|c|c|c|c|}
\hline & $\mathbf{M}$ & SD & 1 & 2 & 3 & 4 & 5 & 6 & 7 & 8 & 9 & 10 & 11 & 12 & 13 \\
\hline 1 & 1.74 & 0.76 & 1.00 & & & & & & & & & & & & \\
\hline 2 & 2.01 & 0.85 & $0.89 * *$ & 1.00 & & & & & & & & & & & \\
\hline 3 & 1.40 & 0.91 & $0.84 * *$ & $0.50 * *$ & 1.00 & & & & & & & & & & \\
\hline 4 & 3.40 & 0.74 & $-0.29 * *$ & $-0.19 *$ & $-0.32 * *$ & 1.00 & & & & & & & & & \\
\hline 5 & 3.40 & 0.75 & $-0.25 * *$ & -0.15 & $-0.30 * *$ & $0.93 * *$ & 1.00 & & & & & & & & \\
\hline 6 & 3.58 & 0.90 & $-0.36 * *$ & $-0.26 * *$ & $-0.37 * *$ & $0.93 * *$ & $0.78 * *$ & 1.00 & & & & & & & \\
\hline 7 & 3.26 & 0.75 & $-0.18^{*}$ & -0.11 & $-0.22 * *$ & $0.93 * *$ & $0.80 * *$ & $0.79 * *$ & 1.00 & & & & & & \\
\hline 8 & 3.64 & 0.66 & $-0.44 * *$ & $-0.38 * *$ & $-0.39 * *$ & $0.40 * *$ & $0.39 * *$ & $0.41 * *$ & $0.31 * *$ & 1.00 & & & & & \\
\hline 9 & 3.46 & 0.71 & -0.14 & -0.10 & -0.15 & $0.30 * *$ & $0.31 * *$ & $0.27 * *$ & $0.26 * *$ & $0.31 * *$ & 1.00 & & & & \\
\hline 10 & 3.80 & 0.52 & $-0.41 * *$ & $-0.32 * *$ & $-0.40 * *$ & $0.27 * *$ & $0.25 * *$ & $0.32 * *$ & $0.18 *$ & $0.34 * *$ & $0.21 * *$ & 1.00 & & & \\
\hline 11 & 4.00 & 0.57 & $-0.37 * *$ & $-0.25 * *$ & $-0.40 * *$ & $0.34 * *$ & $0.37 * *$ & $0.33 * *$ & $0.23 * *$ & $0.26 * *$ & $0.19 *$ & $0.49 * *$ & 1.00 & & \\
\hline 12 & 3.49 & 0.59 & $-0.41 * *$ & $-0.33 * *$ & $-0.40 * *$ & $0.30 * *$ & $0.31 * *$ & $0.25 * *$ & $0.26 * *$ & $0.26 * *$ & $0.41 * *$ & $0.37 * *$ & $0.36^{* *}$ & 1.00 & \\
\hline 13 & 3.60 & 0.58 & $-0.27 * *$ & $-0.18 *$ & $-0.28 * *$ & $0.37 * *$ & $0.35 * *$ & $0.35^{* *}$ & $0.34 * *$ & $0.26 * *$ & $0.33 * *$ & $0.48 * *$ & $0.44 * *$ & $0.59^{* *}$ & 1.00 \\
\hline
\end{tabular}

a. 1. Burnout, 2. Exhaustion, 3. Cynicism, 4. Engagement, 5. Vigor, 6. Dedication, 7. Absorption, 8.

Workload, 9. Control, 10. Reward, 11. Community, 12. Fairness, 13. Values.

b.**. Correlation is significant at the 0.01 level (two-tailed).

c. *Correlation is significant at the 0.05 level (two-tailed). 


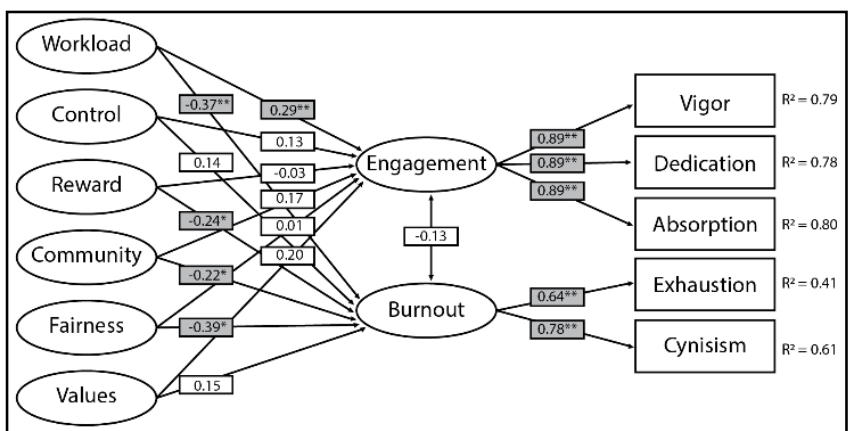

Fig. 2. Path Analysis Result

\section{Model Testing}

This analysis was designed to (1) test the overall fit of the hypothesized model and (2) explore the path relationship between the variables included in the model. The SEM analysis confirmed a good fit of the model to the data $\left(\chi^{2}(22)=36.31, \mathrm{CFI}=0.98\right.$, RMSEA $=0.06$ [90\% CI 0.02, $0.10]$, SRMR $=0.03$ ). Not all the paths were significant. Fig. 2 shows the regression coefficient for each path in the model. The specification process led to the identification of 10 significant paths (see Fig. 2).

The path includes a significant positive path between engagement and the dimensions consisting of vigor, dedication, and absorption; a significant positive path was found from burnout to exhaustion and cynicism; a significant positive path was found from workload to engagement; a significant negative path was found from workload, reward, community, and fairness to burnout. Concerning burnout experiences, the incongruence between employee and the work-life area of perceived fairness, workload, reward, and community was found to be the most reliable predictor. In the case of engagement experiences, the most substantial predictor was perceived workload.

\section{Discussion}

The goal of this study is to enhance the understanding of employees' well-being experience described as the feelings of burnout and engagement. This study investigates how employees' perception of their work environment quality predicts their work experience, described as burnout and engagement. In order to answer this question, a model has been proposed (see Fig. 1). The result indicates a significant relationship exists between workload and engagement; another was found between fairness, workload, reward, community, and burnout (see Fig. 2). The implication of this result is that it helps organizations determine the focus of intervention design that might move employees toward engagement, rather than burnout.

First, the results of the presented study are in line with existing research in which work engagement is measured using the UWES and is characterized by vigor, dedication, and absorption, whereas its negative antithesis, burnout, is described as the feeling of exhaustion and cynicism toward one's job. Next, concerning the degree of match between a person and the six domains of the work environment, burnout is shown to be determined by a misfit in workload, reward, community, and fairness. 
A mismatch in workload is described as work conditions in which too many demands exhaust the individual's energy to the extent where recovery becomes impossible. When there is a misfit between qualitative or quantitative workload and employees' capacity to manage them, the capacity of the employee to meet the demands of the job depletes (Maslach \& Leiter, 2010). In this condition, the employee reports they do not have enough time to do what is essential in their job. Therefore, it takes their off-work time away. There is almost no opportunity for the exhausted employees to rest and restore their energy resources, which deplete over time and put them on the edge of experiencing burnout.

On the other hand, a match between the employee and the job in the area of manageable workload was found to be predictive of engagement. This bi-directional relationship between perceived workload and burnout-engagement experiences also found in Mojsa-Kaja, Golonka, and Marek (2015). The research was conducted in a group of 205 Polish teachers. The ANOVA and Tuckey's post hoc test results showed participants experiencing burnout reported a perceived higher level of mismatch between themselves and the job in the area of manageable workload compared with the participants who experienced work engagement. When employees perceive they have enough resources to manage and settle their workload, it provides opportunities for them to use and refine their existing skills and build expertise. Employees who work in a resourceful work environment are predicted to have higher engagement.

The next mismatch involves a lack of reciprocity between the rewards and the work people do. Employees experiencing misfit in the reward area feel their work is underappreciated and unnoticed. This may involve insufficient financial rewards and/or lack of social rewards. A lack of satisfaction and recognition from others contributes to the development of inefficacy and meaninglessness, which lead to cynicism. This result corresponds to the model of effort-reward imbalance (Siegrist, 2017). A lack of reciprocity between costs (effort spent for work) and gains (financial, institutional, social, or intrinsic rewards) puts employees at a vulnerability of experiencing a state of emotional distress, which in the long run leads to burnout.

Third, the mismatch between the employee and the areas of the community is predictive of burnout. In workplaces where employees perceive the lack of a positive and supportive environment, social contact becomes impersonal. In the extreme, this involves isolative job conditions or one in which chronic and unresolved conflict exists; there is a constant negative feeling of frustration and hostility. The employee working in this environment experiences a constant tension, which exhausts his/her emotional resources. As explained by Maslach (2018), this condition produces a downward spiral of an uncivil and mean-spirited work community that ends up leading to burnout.

The same negative relationship between social environment and burnout was also found in a study by Charoensukmongkol, Moqbel, and Gutierrez-Wirsching (2016). They conducted research using a sample of 174 personnel of two state universities in South Texas. The results showed co-worker and supervisor support had a negative association with burnout (Charoensukmongkol et al., 2016). In general, employees favored with good support from co- 
workers and supervisors tended to report lower burnout symptoms. In depth, researchers found different types of support would buffer the impact of particular components of burnout.

When employees perceive they have supportive co-workers, it helps them experience less emotional exhaustion and cynicism. Therefore, an absence of support from co-workers may generate the feeling of being alienated. This experience, then, causes them to become demotivated about work. On the other hand, when employees perceive they have a supportive supervisor, it lowers their reported exhaustion and cynicism. This pleasant experience also actively helps them to be more confident in their work. Thus, a lack of support from managers can cause employees to feel demotivated about achieving high job performance.

Finally, a mismatch in the fairness area is characterized by unfair treatment described as favoritism and discrimination in the workplace. The mismatch in this domain is listed as the primary predictor of burnout. Unfairness is perceived when employees find there is no organizational justice practice in the workplace as important decisions are determined by the interest of a powerful individual or group (Maslach \& Leiter, 2003). This unfortunate situation leads to moral degradation and the disappearance of loyalty, which begins the cycle of burnout (Wilson, 2016). In their research, Mojsa-Kaja et al. (2015) found that misalignment between people's expectations of fairness and the perceived fairness they received provoked cynicism sentiments toward their job. A lack of perceived fairness leads to job strain, and consequently results in professional burnout.

\section{Conclusions and Limitations}

The result of this paper provides new insight into how the degree of fit between the employee and their work environment predicts their experiences of burnout and engagement. This research is the first to include engagement and burnout constructs within one model tested in the Indonesian workforce. As the model was constructed with the objective of describing the relationship at play, the manager could interpret and utilize the knowledge from the output as a guide to design an organizational development strategy. This improvement program is designed to prevent burnout and foster engagement in the workplace.

The identification of the six areas of person-job misfit expands the spectrum of available options for intervention intended to enhance employees' experience in their work-life, especially in workload, reward, community, and fairness areas, as this study discovered. Employees' thoughts and feelings are not under management's direct control but are accessed indirectly through changes in the work environment. Therefore, the objective is to move employees away from burnout experience and to enhance engagement.

The organization encourages designing a workplace in which the employee has an open opportunity for learning and is provided sufficient resources. This strategy aims to enhance employee ability to cope with the challenging workload. By expanding employee access to valuable job resources, management enables employees to experience vigor, dedication, and absorption while they are working (Hakanen, Bakker, \& Demerouti, 2005). Top management 
should be committed to providing resourceful workplaces. This approach can be implemented by increasing variability in the required skills in the job.

Another example is by initiating a communication channel to facilitate contact between coworkers through open discussion or sharing sessions. Involving external stakeholders also has a significant effect, such as creating the job design to enhance an intense and positive contact with the customer or relevant community. This practice also helps increase favorable social climate in the workplace. A stable, relatively pleasant, and productive community is also substantial for the employees to finish their work, rather than a dysfunctional, oppressive, mean-spirited, or even abusive environment in which burnout is likely to arise. To strengthen social support among employees and supervisors, management should translate this intention into organization policies (Charoensukmongkol et al., 2016) or include it as part of the organization culture.

To acquire more favorable fit in fairness and reward areas, there are various compensation models, such as variable pay based on performance goals, annual prizes and awards, or a distinctive compensation package. The focus is not only on the design of the reward model implemented but also on how it is delivered in an open and fair system. Another alternative available is an improvement of promotion prospects, enrichment of tasks, provision of support, and investment in continued training programs. This intervention alternative is aimed at applying the adaptation and regulation on job demands and strengthening opportunities for adequate occupational rewards (Vegchel, Jonge, Meijer, \& Hamers, 2001) to diminish burnout.

The organization can also use the MBI-GS, the UWES, and the AWS as an organizational regular "checkup" to customize their tailor-made development strategy. The result will help management to identify in advance individuals or groups who are at a higher risk of experiencing burnout. This survey also generates a profile of the strengths and strains of an organizational or work unit. Furthermore, the identified problematic work-life area can then be managed by targeted interventions.

While the number of the responses collected was adequate for the analysis to perform, the inclusion of an additional sample for future studies would have further strengthened the model proposed. The strengths of the data set used include the representation of various organizations, but the generalizability of the model is limited to the population with the same characteristics because the data were collected from a non-probability sample. In this sense, future research should choose the right sample to represent the population in the target.

\section{References}

Bakker, A. B., Albrecht, S. L., \& Leiter, M. P. (2011). Key questions regarding work engagement. European Journal of Work and Organizational Psychology, 20(1), 4-28. doi:10.1080/1359432X.2010.485352

Christianty, T. O., \& Widhianingtanti, L. T. (2016). Burnout Ditinjau dari employee engagement pada Karyawan. Psikodimensia, 15(2), 351-373.

Charoensukmongkol, P., Moqbel, M., \& Gutierrez-Wirsching, S. (2016). The role of co-worker and supervisor support on job burnout and job satisfaction. Journal of Advances in Management Research, 13(1), 4-22. doi:10.1108/JAMR-06-2014-0037 
Gallup. (2013). The state of the American workplace: Employee engagement insights for U.S. business leaders. Washington, D.C.: Gallup, Inc.

Gallup. (2013). The wtate of the global workplace: Employee engagement insights for business leaders worldwide. Washington, D.C: Gallup, Inc.

Gonzalez-Roma, V., Schaufeli, W. B., Bakker, A. B., \& Lloret, S. (2006). Burnout and work engagement: Independent factors or opposite poles? Journal of Vocational Behavior, 68(1), 165-174. doi:10.1016/j.jvb.2005.01.003

Hikmatullah, F. (2017). Hubungan employee engagement dan burnout pada Karyawan Divisi IT. Jurnal Ilmiah Psikologi, 9(1), 100-108.

Hakanen, J. J., Bakker, A. B., \& Demerouti, E. (2005). How dentists cope with their job demands and stay engaged: the moderating role of job resources. European Journal of Oral Sciences, 113, 479-487. doi:10.1111/j.1600-0722.2005.00250.x

Hu, Li-tze., \& Bentler, P. M. (1999). Cutoff criteria for fit indexes in covariance structure analysis: Conventional criteria versus new alternatives. Structural Equation Modeling: A Multidisciplinary Journal, 6(1), 1-55. doi:10.1080/10705519909540118.

Kronos Incorporated. (2017, January 09). The employee burnout crisis: Study reveals big workplace challenge in 2017. Retrieved from Kronos Incorporated: https://www.kronos.com/about-us/newsroom/employeeburnout-crisis-study-reveals-big-workplace-challenge-2017

Leiter, M. P., \& Maslach, C. (2003). Areas of worklife: A structured approach to organizational predictors of job burnout. In P. L. Perrewe, \& D. C. Ganster, Emotional and Physiological Processes and Positive Intervention Strategies, 91-134. Bingley: Emerald Group Publishing Limited.

Leiter, M. P., \& Bakker, A. B. (2010). Work engagement: Introduction. In A. B. Bakker, \& M. P. Leiter, Work engagement: A handbook of essential theory and research, 1-9. Psychology Press: Hove.

Leiter, M. P., \& Maslach, C. (2000). Areas of worklife survey [measurement instrument]. Retrieved from Mind Garden: https://www.mindgarden.com/274-areas-of-worklife-survey

Maslach, C., \& Leiter, M. P. (2010). Reversing burnout: How to rekindle your passion for your work. IEEE Engineering Management Review, 38(4), 91-96. doi:10.1109/EMR.2010.5645760

Maslach, C., Schaufeli, W. B., \& Leiter, M. P. (2001). Job burnout. Annual Review of Psychology, $397-422$. doi:10.1146/annurev.psych.52.1.397

Memon, M. A., Salleh, R., Nordin, S. M., Cheah, J.-H., Ting, H., \& Chuah, F. (2018). Person-organisation fit and turnover intention: The mediating role of work engagement. Journal of Management Development, 37(3), 285-298. doi:10.1108/JMD-07-2017-0232.

Mojsa-Kaja, J., Golonka, K., \& Marek, T. (2015). Job burnout and engagement among teachers-worklife areas and personality traits as predictors of relationships with work. International Journal of Occupational Medicine and Environmental Health, 28(1), 102-119. doi:10.13075/ijomeh.1896.00238

Maslach, C. (2018). Burnout and engagement in the workplace: New perspectives. European Health Psychologist, 13(3), 44-47.

Maslach, C., Jackson, S. E., Leiter, M. P., \& Schaufeli, W. B. (1996). MBI: General survey [measurement instrument]. Retrieved from Mind Garden: https://www.mindgarden.com/312-mbi-general-survey

Schaufeli, W. B., Salanova, M., Gonzalez-Roma, V., \& Bakker, A. B. (2002). The measurement of engagement and burnout: A two sample confirmatory factor analytic approach. Journal of Happiness Studies, 3(1), 71-92. doi:10.1023/A:1015630930326

Schaufeli, W. B., Leiter, M. P., \& Maslach, C. (2009). Burnout: 35 years of research and practice. Career Development International, 14(3), 204-220. doi:10.1108/136204309109664

Schaufeli, W. B., \& Bakker, A. (2003). Utrecht work engagement scale [measurement instrument]. Retrieved from Website of Wilmar Schaufeli: https://www.wilmarschaufeli.nl/tests/\#engagement

Saks, A. M. (2006). Antecedents and consequences of employee engagement. Journal of Managerial Psychology, 21(7), 600-619. doi:10.1108/02683940610690169

Schaeffer, C. (2018, July 03). The productivity and payback of employee engagement. Retrieved from Customer Think: http://customerthink.com/the-productivity-and-payback-of-employee-engagement/

Siegrist, J. (2017). The effort-reward imbalance model. In C. L. Cooper, \& J. C. Quick, The handbook of stress and health: A guide to research and practice (24-35). Chichester: Wiley Blackwell. 
Taris, T. W., Schaufeli, W. B., \& Shimazu, A. (2010). The push and pull of work: The differences between workaholism and work engagement. In A. B. Bakker, \& M. P. Leiter, Work engagement: A handbook of essential theory and research, 39-53. Hove: Psychology Press.

VITAL WorkLife. (2018, March 01). Infographic: The real cost Of burnout. Retrieved from VITAL WorkLife: http://insights.vitalworklife.com/blog/2018/03/01/infographic-the-real-cost-of-burnout

Vegchel, N. V., Jonge, J. d., Meijer, T., \& Hamers, J. P. (2001). Different effort constructs and effort-reward imbalance: Effects on employee well-being in ancillary health care workers. Journal of Advanced Nursing, 34(1), 128-136. doi:10.1046/j.1365-2648.2001.3411726.x

Wigert, B., \& Agrawal, S. (2018, July 12). Employee burnout, part 1: The 5 main causes. Retrieved from Gallup: https://www.gallup.com/workplace/237059/employee-burnout-part-main-causes.aspx

Wilson, F. L. (2016). What is the impact of job burnout antecedents on Georgia nursing home administrators? American Journal of Health Sciences, 7(1), 31-38. doi:10.19030/ajhs.v7i1.9695 